Research Paper:

\title{
Evaluation of the Drug Hypersensitivity Reactions Prevalence in Hospitalized Children in Sari City from 2014 to 2018: An Original Research
}

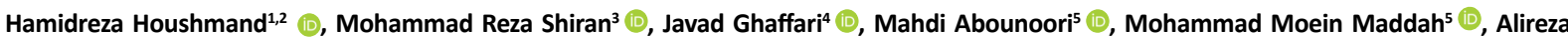 \\ Razavi $^{5}$ (D) Sajjad Askari ${ }^{5}$, Sara Bayat ${ }^{6}$ (D) , Gholamreza Houshmand $^{3^{*}}$ (iD) \\ 1. Department of Pediatrics, Division of Allergy and Clinical Immunology, School of Medicine, Urmia University of Medical Sciences, Urmia, Iran \\ 2. Allergy Research Center, Shiraz University of Medical Sciences, Shiraz, Iran. \\ 3. Department of Pharmacology, Faculty of Medicine, Mazandaran University of Medical Sciences, Sari, Iran. \\ 4. Department of Immunology and Allergy, Bou Ali Sina Hospital, Mazandaran University of Medical Sciences, Sari, Iran. \\ 5. Student Research Committee, School of Medicine, Mazandaran University of Medical Sciences, Sari, Iran. \\ 6. Department of Internal Medicine, Faculty of Medicine, Mazandaran University of Medical Sciences, Sari, Iran.
}

\begin{tabular}{|c|c|}
\hline $\begin{array}{l}\text { Use your device to scan } \\
\text { and read the article online }\end{array}$ & Citation Houshmand HR, Shiran MR, Ghaffari J, Abounoori M, Maddah MM, Razavi AR, et al. Evaluation of the Drug Hy- \\
\hline 口:祘回 & persensitivity Reactions Prevalence in Hospitalized Children in Sari City from 2014 to 2018: An Original Research. Journal of \\
\hline trisyth & Pediatrics Review. 2021; 9(3):229-238. http://dx.doi.org/10.32598/jpr.9.3.910.1 \\
\hline arys & doilhttp://dx.doi.org/10.32598/jpr.9.3.910.1 \\
\hline
\end{tabular}

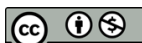

Article info:

Received: 14 May 2020

First Revision: 07 Jul 2020

Accepted: 17 Feb 2021

Published: 01 July 2021

\section{A B STR A C T}

Background: Drug allergy is a subtype of Adverse Drug Reaction (ADR) mediated by the immunologic system. Extreme drug allergy is poorly known in children that contribute to hospitalization in our region.

Objectives: This research aimed to study major drug hypersensitivity reactions in the north of Iran among the hospitalized children.

Methods: This cross-sectional study was conducted at Bou Ali Sina Hospital in the north of Iran. We analyzed the medical files of 140 children admitted to the hospital with drug allergies from 2014 to 2018. The inclusion criteria were based on the DRESS (drug reaction with eosinophilia and systemic symptoms) scoring system, and those who scored more than four were enrolled. Patients with incomplete medical charts were excluded. The sampling methodology was based on the consecutive census method.

Results: In the current study, 62 patients were females (44.29\%), and 78 were males (55.71\%). Ninety-six cases (68.57\%) were children under five, and 44 cases (31.43\%) were over five years old. Most ADRs were seen in patients from urban areas $(58.57 \%)$ than in rural areas (41.43\%). In 116 children (82.6\%), maculopapular rashes were seen. Phenobarbital and cefalexin had the highest levels of drug reactions, including 85 persons $(55.19 \%)$ and 18 persons $(11.69 \%)$ respectively. Pruritus, fever, and scaling were the most common symptoms observed in the patients. The most commonly used treatment was antihistamines.

Conclusions: The most causative medication inducing ADR was phenobarbital. The maculopapular rash was the most common skin manifestation, and there were no relationships between sex, age, medication type, and type of hypersensitivity reactions.

* Corresponding Author:

Gholamreza Houshmand, PhD.

Address: Department of Pharmacology, Faculty of Medicine, Mazandaran University of Medical Sciences, Sari, Iran.

Tel: +98 (151) 3543081-3

E-mail:dr.houshmand_pharmaco@yahoo.com 


\section{Context}

rug consumption during disease might cause some Adverse Drug Reactions (ADRs). Adverse drug reactions occur in $5 \%$ to $50 \%$ of cases due to different drugs and different therapeutic periods. As an example, ADR could happen in $50 \%$ of patients during chemotherapy. ADR accounts for $7.6 \%$ of the hospitalized patients with $32 \%$ mortality [1].

In recent years, hypersensitivity reactions such as immediate and late forms have become an unacceptable and significant concern [2, 3]. The immediate type, such as IgE-mediated reactions, occurs about one hour after drug consumption, accompanied by severe cutaneous adverse reactions [4]. Drug Reaction with Eosinophilia and Systemic Symptoms (DRESS), Stevens-Johnson Syndrome (SJS), and Toxic Epidermal Necrolysis (TEN) are indicative of the late-type hypersensitivity reaction [4-6].

About $45 \%$ of $A D R s$ in children are caused by $\beta$-lactam antibiotics and $23 \%$ by non- $\beta$-lactam types $[7,8]$. Hypersensitivity to vancomycin, aminoglycosides, tetracycline, and quinolones is rare because of their prescription restrictions in children [9]. Ibuprofen and paracetamol are the most common Non-Steroidal Anti-Inflammatory Drugs (NSAID), which can cause drug second type of allergy [10].

Skin reactions and respiratory symptoms are the most common symptoms in ADRs. The NSAIDs are chronic hive resonators in adults, whereas there is no available data for children [11]. The NSAIDs are the most related drug to SJS in comparison to other drugs [12]. Katayama et al. study of ADR caused by contrast and intravenous agents reported severe heart and respiratory diseases, which occur with the possibility of $0.07 \%$ in children under 20 years [13].

Maculopapular Exanthema (MPE) is the most common skin symptom, especially in treatment with $\beta$-lactam antibiotics and non- $\beta$-lactam antibiotics, NSAIDs, and anticonvulsant medications. Immediate skin symptoms like hives, itching, and erythema are related to $\beta$-lactam antibiotics, sulfonamides, NSAIDs, and N-nitroso-Nmethyl-4-aminobutyric acid [14].

Respiratory symptoms can be a part of an anaphylactic reaction. This reaction is more dangerous in children with asthma. Late-phase hypersensitivity reactions like pneumonia are rare in children in the therapeutic period except for chemotherapy [15].
Drugs ceasing during sensitivity is the best treatment for ADRs. For example, $\beta$-lactam antibiotics, the drug of choice for many infections in children, are numbered as the most common culprit drug for ADRs. Other antibiotics used in adults like tetracycline and quinolones cause ADRs, which are prohibited in children [2]. Still, there is limited information about ADR in children in the north of Iran. So, we aimed to investigate adverse drug reactions in children admitted to one of the major pediatric specialized hospitals in the north of Iran.

\section{Materials and Methods}

\section{Study population}

The present cross-sectional study aimed to evaluate ADR in 140 children admitted from 2014 to 2018 to Bou Ali Sina Hospital in Sari City, Iran. We extracted the age, gender, type of drug reaction, clinical symptoms, treatment plan, and culprit drug from their medical chart. The inclusion criteria were based on the DRESS scoring system, and the patients whose scoring number was more than four were entered into the study [16]. Patients with incomplete medical charts were excluded from the study. The sampling methodology was based on the consecutive census method.

\section{Behavioral assessing}

We obtained permission to conduct the research from the relevant authorities and the Ethics Committee for ethical considerations. All participants and relevant authorities were also assured that medical information in medical charts would not be discussed throughout the research process. The study was approved by Ethics Review Committee of the Mazandaran University of Medical Sciences (Code: IR.MAZUMS.REC.2019.498).

\section{Statistical analysis}

The Graph Pad Prism version 5 was applied for information analysis. The mean, variance, frequency, and percentage were used to describe quantitative variables. To evaluate the correlation between quantitative variables, the Pearson coefficient or Spearman coefficient was determined. Also, the Chi-square and Fisher exact test were used for the correlation between qualitative variables. $P$ values less than 0.05 were considered significant. 


\section{Results}

In this cross-sectional study, 140 children were studied. Among the subjects, 78 (55.71\%) were male, and 62 (44.29\%)were female ( $P>0.05)$. The subjects' average (SD) age was 7.43 (4.09) years, with a minimum age of one month and a maximum of 14 years. Ninety-six cases $(68.57 \%)$ were children under the age of five, and 44 cases (31.43\%) were children over the age of 5. Eighty-two cases $(58.57 \%)$ lived in the city and 58 cases $(41.43 \%)$ in the village. Thirty-five cases $(25.00 \%)$ had a history of the previous drug hypersensitivity, and 11 cases (7.86\%) had a family history of drug hypersensitivity. Of 140 patients who were studied, 116 (82.86\%) had a maculopapular rash, 27 (19.28\%) erythroderma, 5 (3.57\%) SJS, 4 (2.86\%) erythema multiform, and 2 (1.43\%) TEN. Table 1 presents the demographic variables, clinical symptoms, and types of treatment. Our analyses revealed no significant difference $(P>0.05)$ between the two sexes. Phenobarbital, cefalexin, and sodium valproate were the most common culprit drugs, which were significantly different from other medications. Pruritus, fever, and scaling were the most common symptoms observed in patients. The most commonly used treatment was antihistamines (Table 1). In univariate analyses, there were no significant relationships between the type of hypersensitivity reaction with age $(P=0.930)$, sex $(P=0.320)$, and allergic drug $(P=0.095)$. The frequency of hypersensitivity reactions based on sex, age, and type of drug are shown in Figures 1, 2 \& 3 respectively.

\section{Discussion}

Pediatric patients are prone to ADR because medications' pharmacokinetics and pharmacodynamics have less been studied in these age groups. Also, drug absorption and metabolism are more variable in children [17]. The pharmaceutical business has little motivation to develop and manufacture guidelines on specific drug doses for children due to few therapeutic ranges. Besides, expensive studies are required for various age groups (newborns, infants, children, adolescents) due to the continual metabolic changes [18].

Although most drugs are not chemically reactive on their own (penicillin is a notable exception), they will be triggered within the body system by binding covalently with cellular macromolecules and thereby acting as an antigen resulting in the formation of particular antibodies and or T lymphocytes. Toxicity occurs if the balance between the activation of drugs and detoxification is changed. Thus, the ADR may proceed with the accumulated amounts of enzymes involved in bioactivation and or a reduction in detoxification mechanisms [19]. Another theory postulates that drug attachment to the mixture of major histocompatibility complex peptide and $T$ cell receptor offers a model of drug stimulation of metabolism-independent $T$ cells that explains the appearance of drug hypersensitivity reaction in organs such as skin without metabolism of active drugs [20].

In the current study, the most frequent ADR was significantly seen in children under five. However, the high frequency of ADR in male children (55.71\%) versus females (44.29\%) was not significant. In a systematic review study of 76 patients, the highest ADR rate was reported in children under four years old, and most of them were females [21]. In a similar study, Nabavizadeh et al. reported that almost all ADR (57.9\%) was seen in females [3]. Nevertheless, in a different survey conducted on children under two years old, ADR was seen in male children (57\%) more than females (43\%) [22]. Moreover, during a tertiary care hospital study in Northern Brazil, the same results with our research were reported that the highest rate of ADR in patients between 0 and 18 years old was seen in males (55.7\%) more than females [23]. These variations are because of different sample sizes.

Most drug reactions were significantly caused by phenobarbital, $\beta$-lactams, and sodium valproate in the current study. Bourgeois et al. reported that antimicrobial agents were the main medication categories with drug reactions and were regularly seen in patients under four years old. The central nervous system medications and hormones were reported with a high rate of causing ADR in the next rank [24]. Based on a systematic analysis in two children's hospitals in an African region, systemic antibacterials, systemic corticosteroids, antivirals, psycholeptics, immunosuppressants, and analgesics were the most common categories of drugs involved in ADR [25]. $\beta$-Lactams and phenobarbital were the drugs that caused the most adverse reactions in a similar study in the southeast of Iran [3]. Zambonino et al. additionally confirmed the identification of $\beta$-lactam hypersensitivity in seven (92\%) cases with the most frequency [26]. In the current study, many children diagnosed with epilepsy and seizures in the Pediatric Ward have received phenobarbital. It is an accessible and convenient drug at a low cost. So it could be a reason for various drug reactions reported for phenobarbital.

The development of medication, particularly $\beta$-lactams hypersensitivity reaction, is sometimes explained by the hapten hypothesis [19]. Serum sickness-like reactions are typically ascertained in $\beta$-lactams and are characterized by a skin rash (e.g. erythroderma multiform), 
Table 1. Demographic and clinical characteristics of the patients

\begin{tabular}{|c|c|c|c|}
\hline \multicolumn{2}{|c|}{ Variables } & \multirow{2}{*}{\begin{tabular}{|l} 
No. (\%) \\
$78(55.71)$
\end{tabular}} & \multirow[t]{2}{*}{$\mathbf{P}$} \\
\hline \multirow{3}{*}{ Sex } & Male & & \\
\hline & & & 0.525 \\
\hline & Female & $62(44.29)$ & \\
\hline \multirow{3}{*}{ Age (y) } & $>5$ & $44(31.43)$ & \\
\hline & & & 0.0001 \\
\hline & $<5$ & $96(68.57)$ & \\
\hline \multirow{3}{*}{ Place of residence } & Urban & $82(58.57)$ & \\
\hline & & & 0.043 \\
\hline & Rural & $58(41.43)$ & \\
\hline \multirow{3}{*}{ Family history } & Positive & $35(25)$ & \\
\hline & & & 0.0001 \\
\hline & Negative & $105(75)$ & \\
\hline \multirow{3}{*}{ History of previous allergies } & Positive & $11(7.86)$ & \\
\hline & & & 0.0001 \\
\hline & Negative & 129(92.14) & \\
\hline \multirow{9}{*}{ Accused medication } & Phenobarbital & $85(55.19)$ & \multirow{9}{*}{0.0001} \\
\hline & Cefalexin & 18(11.69) & \\
\hline & Sodium valproate & 19(12.34) & \\
\hline & Lamotrigine & $9(5.84)$ & \\
\hline & & & \\
\hline & Co-amoxiclav & $9(5.84)$ & \\
\hline & Carbamazepine & $6(3.90)$ & \\
\hline & Azithromycin & $4(2.60)$ & \\
\hline & Co-trimoxazole & $4(2.60)$ & \\
\hline \multirow{9}{*}{ Clinical symptoms } & Itching & $60(42.86)$ & \multirow{9}{*}{0.0001} \\
\hline & Fever & 20(14.29) & \\
\hline & Scaling & 13(9.29) & \\
\hline & Vomiting & $10(7.14)$ & \\
\hline & & & \\
\hline & Swelling of the limbs & $9(6.43)$ & \\
\hline & Icter & 5 & \\
\hline & Cough & 4 & \\
\hline & respiratory distress & 2 & \\
\hline \multirow{3}{*}{ Type of treatment } & Antihistamine & 98 & \multirow{3}{*}{0.0001} \\
\hline & Corticosteroid & 62 & \\
\hline & enous Immune Globulin (IVIG) & 6 & \\
\hline
\end{tabular}




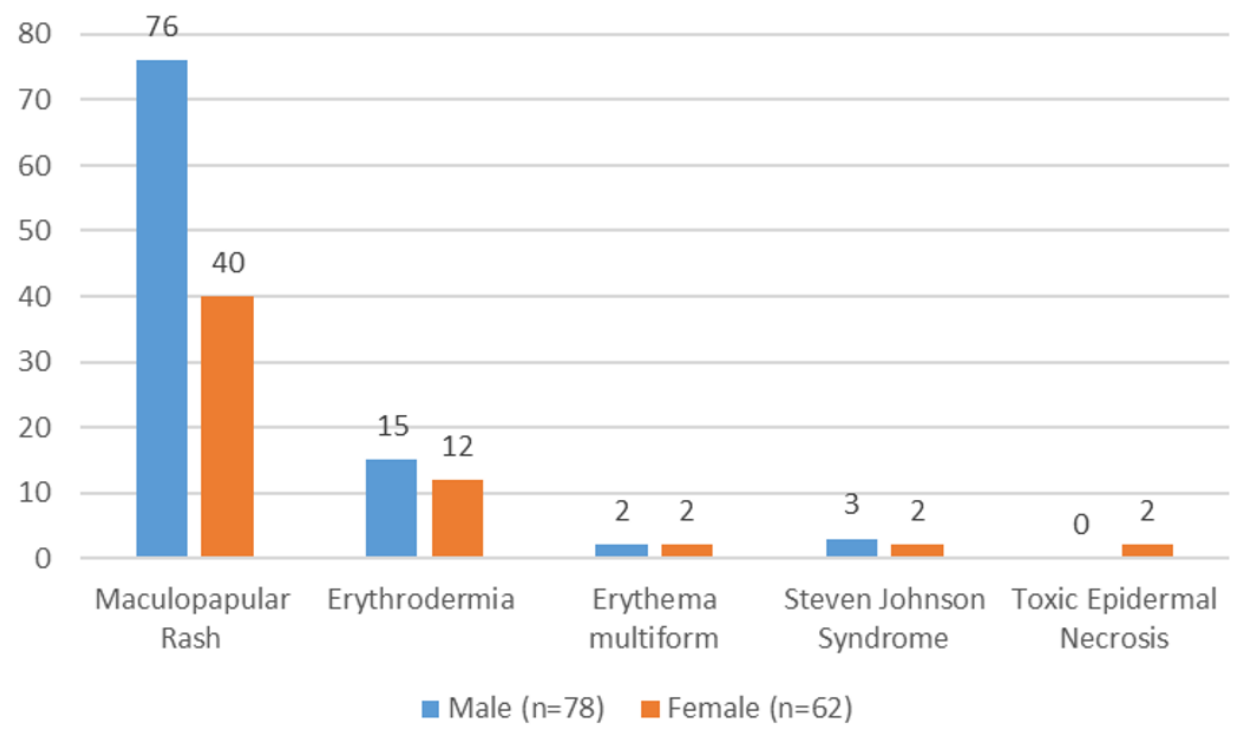

Figure 1. Sex-specific hypersensitivity reactions $(P=0.320)$

Journal of Pediatrics Review

arthropathy, and fever [27]. In an epidemiologic study on ADR in children admitted to the hypersensitivity reaction unit of a tertiary-care pediatric hospital setting, cutaneous type of $\beta$-lactam adverse reaction was reported in great numbers. Additionally, four cases of SJS were reported (three cases with amoxicillin-clavulanic acid and one case with ceftriaxone) [28].

In the present study, the adverse drug effects of $\beta$-lactams were mainly seen after using cefalexin and co-amoxiclav, principally within the type of skin manifestations (maculopapular rash and erythroderma). Also, two cases of SJS were ascertained with cefalexin and co-amoxiclav. Cafarrelli et al. reported that hypersensitivity to $\beta$-lactams, principally amoxicillin-clavulanic acid, is seen in $1.5 \%-12 \%$ of children, whereas the thirdgeneration cephalosporins are less ordinarily involved [28]. In Piccorossi et al. study on $\beta$-lactams antibiotics, amoxicillin-clavulanic acid was most often reported [28]. These different results (with our study results) may be due to the genetics of patients involved, the different prescribed drugs, and the antibiotic resistance pattern in our region. Another reason might be due to the use of these $\beta$-lactams together. The cross-reactions between penicillin and cephalosporins are due to the side chain's molecular structure placed in position -7 of the $\beta$-lactam ring. This adverse event has been reported in less than $10 \%$ of patients with a hypersensitivity reaction [29].

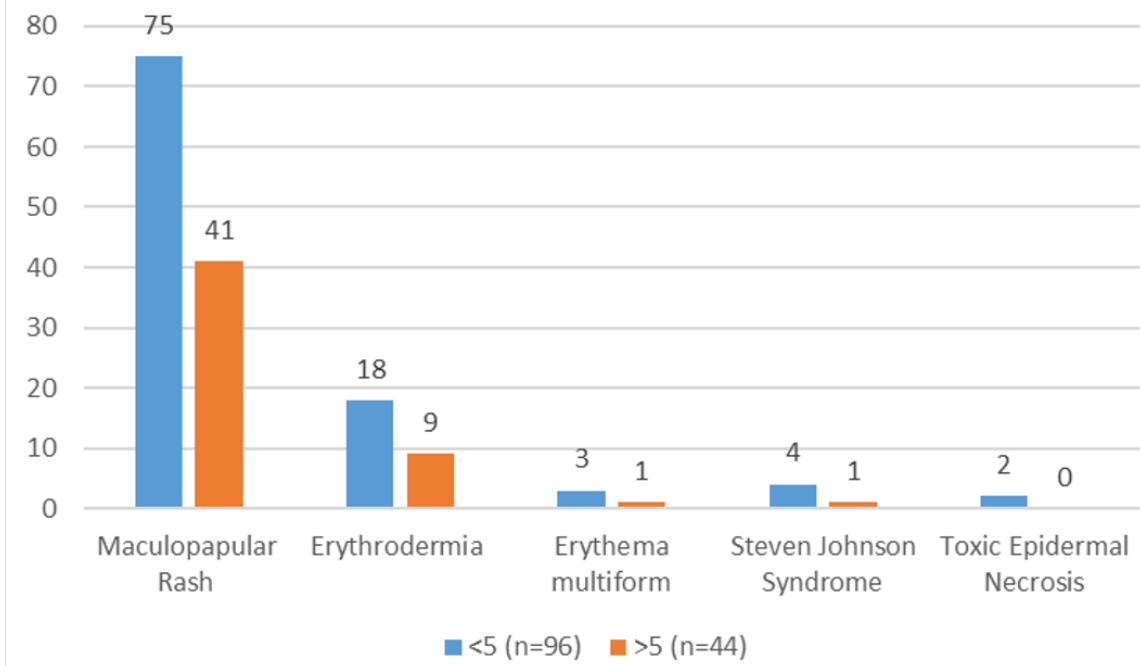

Figure 2. Type of age-specific hypersensitivity reaction $(P=0.930)$ 


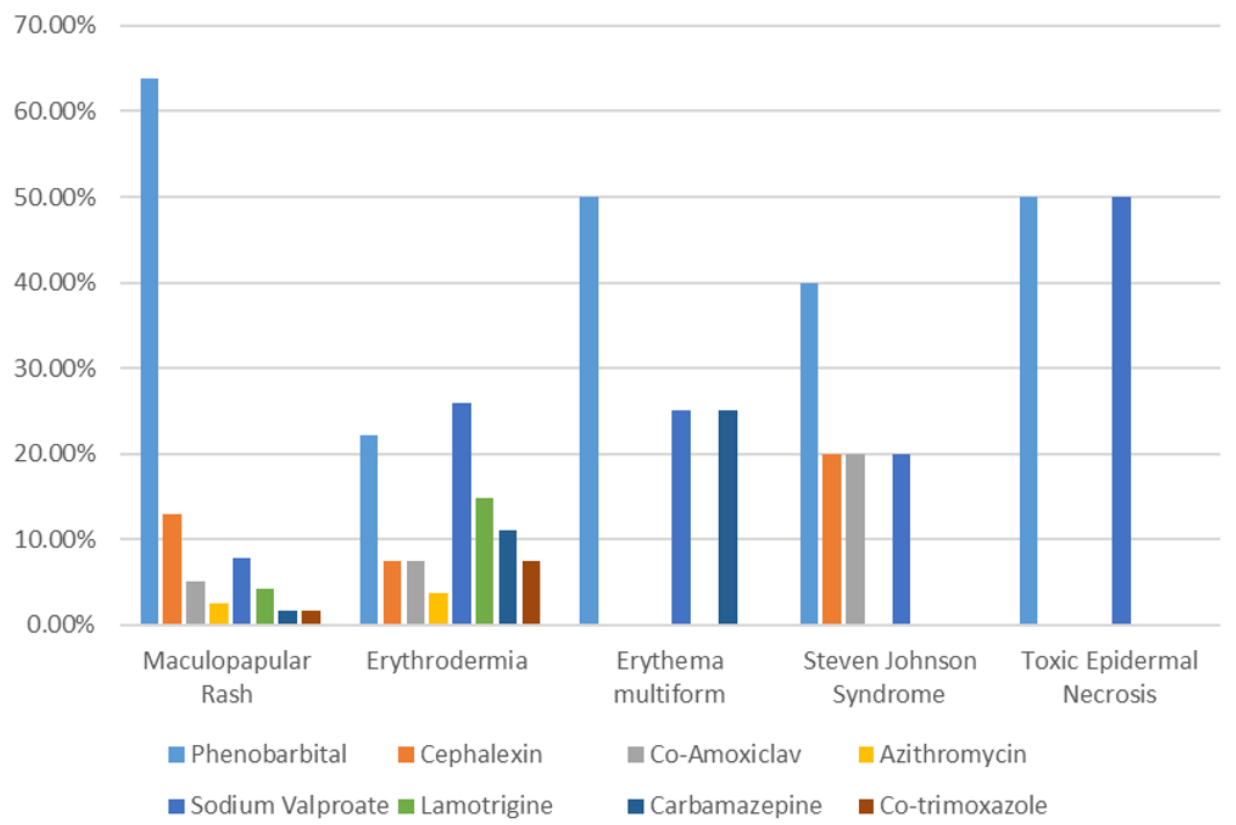

Figure 3. Type of medication used with hypersensitivity reaction ( $P=0.095)$

Journal of Pediatrics Review

As mentioned above, phenobarbital was the anticonvulsant drug with the most ADRs (mostly with maculopapular rash) in our study. In the Karimzadeh et al. research, children under four were studied with an antiepileptic drug for adverse reactions from 2010 to 2012. The most commonly reported adverse effects were maculopapular rash, and phenobarbital was the main culprit. More reactions than non-aromatic ones have been seen in aromatic anticonvulsant medications. Since it is an aromatic drug and cheap, it is often used, so ADR ordinarily was seen after using phenobarbital [30].

In the current study, the most clinical symptoms that trigger medication-related damage on admission were itch (42.86\%) and fever (14.29\%). The same results were also seen in Takata et al.'s study, where itching was the most common ADR [31].

In drug reactions, the maculopapular rash was reported as the commonest reaction within the current study (97.44\%). It had been almost like an equivalent study in the southeast of Iran (90.9\%) [3]. In a prospective observational study performed on hospitalized children at the Ethiopian University Hospital, most ADR was reported injection site inflammation (pain, swelling, and redness) (22.4\%) and maculopapular skin rash (20.7\%) [32].

Some studies report that sex might influence ADR. Various ADRs were considerably overrepresented in one sex compared to the other $[33,34]$. In our study, the maculopapular rash is often seen in boys. But the difference was not statically significant. There is a huge distinction in the number and kinds of adverse events between the pediatric, adult, and geriatric populations. Therefore, the ADR is different in every medication for every age group [35]. Within the current study, erythema multiform, SJS, and toxic epidermal necrosis were frequent in the under-five age group. In addition, maculopapular rash and erythroderma were common in the age group of higher than five years. But statically, no relationship between the type of hypersensitivity reactions and age was seen

The history of a drug hypersensitivity reaction is supposed to provoke ADR. In a Gomes et al. study, 34 children with a history of drug hypersensitivity reactions participated in a workup. After in vivo, in vitro, and drug provocation tests, only three children (8.8\%) showed ADR [36]. In three studies on 995 children with drug hypersensitivity reaction history, after drug provocation tests, 169 (17.0\%) had a homogenous clinical sign suggesting a drug hypersensitivity reaction [10, 36, 37]. In Nabavizadeh et al. study, family member ADR history and patient past drug hypersensitivity reactions were suggested as two necessary factors for ADR [3]. But based on our results, most of the ADR was seen in children without previous drug allergies or family history. This difference results from totally different patients involved and or misdiagnosis of drug hypersensitivity reaction history. 
Furthermore, the detection of drug hypersensitivity reactions should be based not only on a close clinical background but also on standardized skin tests, accurate in vitro tests, and drug provocation tests wherever possible [38]. It should also be considered that a family member with an allergic disorder may bias toward over-reporting the history of an allergic reaction. In our study, $7.86 \%$ of patients with ADR reported familial drug hypersensitivity reaction history.

According to our study results, children from urban areas (58.57\%) showed ADR more than children from rural areas (41.43\%). Perhaps it is easier to access drug stores in urban areas. In a study evaluating "adverse drug reactions because of opioid analgesic use in New South Wales, Australia", it is reported that patients with ADR are principally from urban areas (99.7\%) [39].

There is some drug-based aid for ADR. According to Nabavizadeh et al. study, prednisolone is used as a remedy for ADR in $63.6 \%$ of cases and Intravenous Immunoglobulin (IVIG) in $46.4 \%$ of cases [3]. In Lobo et al. clinical study, ADR is treated using antihistamines, corticosteroids, antidotes, zinc oxide, and vitamin creams to alleviate symptoms [23]. Antihistamines, corticosteroids, and IVIG were used for clinical medical aid in the current study to relieve adverse drug effects.

\section{Conclusion}

Overall, our findings show that maculopapular rash was the most common ADR skin manifestation in children. The main culprit medication was phenobarbital. Most patients with ADR were under five years old urban children without previous personal and familial allergy histories. Also, the common clinical findings were itching. There is no relationship between hypersensitivity reactions and variables of sex, age, and medication type.

\section{Ethical Considerations}

\section{Compliance with ethical guidelines}

All ethical principles are considered in this article. The participants were informed of the purpose of the research and its implementation stages. They were also assured about the confidentiality of their information and were free to leave the study whenever they wished, and if desired, the research results would be available to them. A written consent has been obtained from the subjects. principles of the Helsinki Convention was also observed. The study was approved by Ethics Review Committee of the Mazandaran University of Medical Sciences (Code: IR.MAZUMS.REC.2019.498).

\section{Funding}

This research did not receive any grant from funding agencies in the public, commercial, or non-profit sectors.

\section{Authors' contributions}

All authors equally contributed to preparing this article.

\section{Conflicts of interest}

All authors declared no conflict of interest.

\section{Acknowledgements}

The authors would like to thank the Student Research Committee of Mazandaran University of Medical Sciences and Bou Ali Sina Hospital staff and all patients and their families for helping us perform this study.

\section{References}

1. Elzagallaai AA, Greff MJ, Rieder MJ. Adverse drug reactions in children: The double-edged sword of therapeutics. Clinical Pharmacology \& Therapeutics. 2017; 101(6):725-35. [DOI:10.1002/cpt.677] [PMID]

2. Gomes ER, Brockow K, Kuyucu S, Saretta F, Mori F, Blanca-Lopez $\mathrm{N}$, et al. Drug hypersensitivity in children: Report from the pediatric task force of the EAACI Drug Allergy Interest Group. Allergy. 2016; 71(2):149-61. [DOI:10.1111/all.12774] [PMID]

3. Nabavizadeh H, Alyasin S, Houshmand H, Houshmand G, Bahadoram $\mathrm{M}$, Bayat $\mathrm{S}$, et al. Drug hypersensitivity reactions in hospital-admitted children: A single center study in southern Iran. Jundishapur Journal of Natural Pharmaceutical Products. 2018; 13(2):e13981. [DOI:10.1111/all.12774]

4. Grassi MFR, Olavarria VN, Kruschewsky RdA, Mascarenhas RE, Dourado I, Correia LC, et al. Human T cell lymphotropic virus type 1 (HTLV-1) proviral load of HTLV-associated myelopathy/ tropical spastic paraparesis (HAM/TSP) patients according to new diagnostic criteria of HAM/TSP. Journal of Medical Virology. 2011; 83(7):1269-74. [DOI:10.1002/jmv.22087] [PMID]

5. Miliszewski MA, Kirchhof MG, Sikora S, Papp A, Dutz JP. Stevens-Johnson syndrome and toxic epidermal necrolysis: An analysis of triggers and implications for improving prevention. The American Journal of Medicine. 2016; 129(11):1221-5. [DOI:10.1016/j.amjmed.2016.03.022] [PMID]

6. Jain A, Yadav A, Bozhkov A, Padalko V, Flora S. Therapeutic efficacy of silymarin and naringenin in reducing arsenicinduced hepatic damage in young rats. Ecotoxicology and Environmental Safety. 2011; 74(4):607-14. [DOI:10.1016/j. ecoenv.2010.08.002] 
7. Macy E, Poon K-Y T. Self-reported antibiotic allergy incidence and prevalence: Age and sex effects. The American Journal of Medicine. 2009; 122(8):778.E1-7. [PMID] [DOI:10.1016/j.amjmed.2009.01.034]

8. Gamboa PM. The epidemiology of drug allergy-related consultations in Spanish Allergology services: Alergológica-2005. Journal of Investigational Allergology \& Clinical Immunology. 2009; 19 Suppl 2:45-50. [PMID]

9. Adefurin A, Sammons H, Jacqz-Aigrain E, Choonara I. Ciprofloxacin safety in paediatrics: A systematic review. Archives of Disease in Childhood. 2011; 96(9):874-80. [DOI:10.1136/ adc.2010.208843] [PMID]

10. Erkoçoğlu M, Kaya A, Civelek E, Özcan C, Çakır B, Akan A, et al. Prevalence of confirmed immediate type drug hypersensitivity reactions among school children. Pediatric Allergy and Immunology. 2013; 24(2):160-7. [DOI:10.1111/ pai.12047] [PMID]

11. Settipane RA, Constattine HP, Settipane GA. Aspirin intolerance and recurrent urticaria in normal adults and children: Epidemiology and review. Allergy. 1980; 35(2):149-54. [DOI:10.1111/j.1398-9995.1980.tb01730.x] [PMID]

12. Ferrandiz-Pulido C, Garcia-Patos V. A review of causes of Stevens-Johnson syndrome and toxic epidermal necrolysis in children. Archives of Disease in Childhood. 2013; 98(12):998-1003. [DOI:10.1136/archdischild-2013-303718] [PMID]

13. Katayama H, Yamaguchi K, Kozuka T, Takashima T, Seez $P$, Matsuura K. Adverse reactions to ionic and nonionic contrast media. A report from the Japanese Committee on the Safety of Contrast Media. Radiology. 1990; 175(3):621-8. [DOI:10.1148/radiology.175.3.2343107] [PMID]

14. Segal AR, Doherty KM, Leggott J, Zlotoff B. Cutaneous reactions to drugs in children. Pediatrics. 2007; 120(4):e108296. [DOI:10.1148/radiology.175.3.2343107] [PMID]

15. Leuppi JD, Schnyder P, Hartmann K, Reinhart WH, Kuhn M. Drug-induced bronchospasm: Analysis of 187 spontaneously reported cases. Respiration. 2001; 68(4):345-51. [DOI:10.1159/000050525] [PMID]

16. Kardaun SH, Sidoroff A, Valeyrie-Allanore L, Halevy S, Davidovici BB, Mockenhaupt $M$, et al. Variability in the clinical pattern of cutaneous side-effects of drugs with systemic symptoms: Does a DRESS syndrome really exist? British Journal of Dermatology. 2007; 156(3):609-11. [DOI:10.1111/j.1365-2133.2006.07704.x] [PMID]

17. Dedefo MG, Mitike AH, Angamo MT. Incidence and determinants of medication errors and adverse drug events among hospitalized children in West Ethiopia. BMC Pediatrics. 2016; 16:81. [DOI:10.1186/s12887-016-0619-5] [PMID]

18. Napoleone E. Children and ADRs (Adverse Drug Reactions). Italian Journal of Pediatrics. 2010; 36:4. [DOI:10.1186/18247288-36-4] [PMID]
19. Riley RJ, Leeder JS. In vitro analysis of metabolic predisposition to drug hypersensitivity reactions. Clinical \& Experimental Immunology. 1995; 99(1):1-6. [DOI:10.1111/j.1365-2249.1995. tb03463.x] [PMID]

20. Khan IU, Bickers DR, Haqqi TM, Mukhtar H. Induction of CYP1A1 mRNA in rat epidermis and cultured human epidermal keratinocytes by benz(a)anthracene and beta-naphthoflavone. Drug Metabolism and Disposition. 1992; 20(5):620-4. [PMID]

21. Marrs T, Fox AT, Lack G, du Toit G. The diagnosis and management of antibiotic allergy in children: Systematic review to inform a contemporary approach. Archives of Disease in Childhood. 2015; 100(6):583-8. [DOI:10.1136/archdischild-2014-306280] [PMID]

22. Moore TJ, Weiss SR, Kaplan S, Blaisdell CJ. Reported adverse drug events in infants and children under 2 years of age. Pediatrics. 2002; 110(5):e53. [DOI:10.1136/archdischild-2014-306280] [PMID]

23. Lobo MG, Pinheiro SM, Castro JG, Momenté VG, Pranchevicius MC. Adverse drug reaction monitoring: Support for pharmacovigilance at a tertiary care hospital in Northern Brazil. BMC Pharmacology and Toxicology. 2013; 14:5. [DOI:10.1186/2050-6511-14-5] [PMID]

24. Bourgeois FT, Mandl KD, Valim C, Shannon MW. Pediatric adverse drug events in the outpatient setting: An 11 year national analysis. Pediatrics. 2009; 124(4):e744-50. [DOI:10.1186/2050-6511-14-5] [PMID]

25. Mouton JP, Fortuin-de Smidt MC, Jobanputra N, Mehta U, Stewart $A$, de Waal $R$, et al. Serious adverse drug reactions at two children's hospitals in South Africa. BMC Pediatrics. 2020; 20:3. [DOI:10.1186/s12887-019-1892-x] [PMID]

26. Zambonino MA, Corzo JL, Muñoz C, Requena G, Ariza A Mayorga $C$, et al. Diagnostic evaluation of hypersensitivity reactions to beta-lactam antibiotics in a large population of children. Pediatric Allergy and Immunology. 2014; 25(1):80-7. [DOI:10.1111/pai.12155] [PMID]

27. Platt R, Dreis MW, Kennedy DL, Kuritsky JN. Serum sicknesslike reactions to amoxicillin, cefaclor, cephalexin, and trimethoprim-sulfamethoxazole. The Journal of Infectious Diseases. 1988; 158(2):474-7. [DOI:10.1093/infdis/158.2.474] [PMID]

28. Piccorossi A, Liccioli G, Barni S, Sarti L, Giovannini M, Verrotti $A$, et al. Epidemiology and drug allergy results in children investigated in allergy unit of a tertiary-care paediatric hospital setting. Italian Journal of Pediatrics. 2020; 46:5. [DOI:10.1186/s13052-019-0753-4] [PMID]

29. Blanca M, Vega J, Garcia J, Miranda A, Carmona M, Juarez C, et al. New aspects of allergic reactions to betalactams: Crossreactions and unique specificities. Clinical \& Experimental Allergy. 1994; 24(5):407-15. [DOI:10.1111/j.1365-2222.1994. tb00928.x] [PMID]

30. Karimzadeh P, Bakrani V. Antiepileptic drug-related adverse reactions and factors influencing these reactions. Iranian Journal of Child Neurology. 2013; 7(3):25-9. [PMID] [PMCID] 
31. Takata GS, Mason W, Taketomo C, Logsdon T, Sharek PJ. Development, testing, and findings of a pediatric-focused trigger tool to identify medication-related harm in US children's hospitals. Pediatrics. 2008; 121(4):e927-35. [DOI:10.1542/peds.2007-1779] [PMID]

32. Eshetie TC, Hailemeskel B, Mekonnen N, Paulos G, Mekonnen $A B$, Girma T. Adverse drug events in hospitalized children at Ethiopian University Hospital: A prospective observational study. BMC Pediatrics. 2015; 15:83. [DOI:10.1186/ s12887-015-0401-0] [PMID]

33. Chaves AC, Seeman MV. Sex selection bias in schizophrenia antipsychotic trials. Journal of Clinical Psychopharmacology. 2006; 26(5):489-94. [DOI:10.1097/01. jcp.0000236652.78168.ee] [PMID]

34. Raz L, Miller VM. Considerations of sex and gender differences in preclinical and clinical trials. In: Regitz-Zagrosek $\mathrm{V}$, editor. Sex and Gender Differences in Pharmacology. Berlin/Heidelberg: Springer; 2012. pp. 127-148. https:// www.google.com/books/edition/Sex_and_Gender_Differences_in_Pharmacolo/-rO2bdyoSEgC

35. Sagreiya H, Chen YR, Kumarasamy NA, Ponnusamy K, Chen D, Das AK. Differences in antipsychotic-related adverse events in adult, pediatric, and geriatric populations. Cureus. 2017; 9(2):e1059. [DOI:10.7759/cureus.1059] [PMID] [PMCID]

36. Rebelo Gomes E, Fonseca J, Araujo L, Demoly P. Drug allergy claims in children: From self-reporting to confirmed diagnosis. Clinical \& Experimental Allergy. 2008; 38(1):191-8. [DOI:10.1111/j.1365-2222.2007.02870.x] [PMID]

37. Karakas T, Orhan F, Kilic I, Baki A, Cakir M. Confirmed prevalence of immunoglobulin E-mediated drug allergy in 6-17-year-old urban schoolchildren in Trabzon, Turkey: A population based study. Allergy. 2011; 66:256. https:// scholar.google.com/scholar?cluster $=80429503512338486$ 29\&hl=en\&oi=scholarr

38. Demoly P, Adkinson NF, Brockow K, Castells M, Chiriac AM, Greenberger PA, et al. International Con sensus on drug allergy. Allergy. 2014; 69(4):420-37. [DOI:10.1111/all.12350] [PMID]

39. Du W, Chong S, McLachlan AJ, Luo L, Glasgow N, Gnjidic $D$. Adverse drug reactions due to opioid analgesic use in New South Wales, Australia: A spatial-temporal analysis. BMC Pharmacology and Toxicology. 2019; 20(1):55. [DOI:10.1186/s40360-019-0333-7] [PMID] 
This Page Intentionally Left Blank 